\title{
(6) OPEN ACCESS \\ Public participation in genetic databases: crossing the boundaries between biobanks and forensic DNA databases through the principle of solidarity
}

\author{
Helena Machado, ${ }^{1}$ Susana Silva ${ }^{2}$
}

${ }^{1}$ Centre for Social Studies, University of Coimbra, Coimbra, Portugal ${ }^{2}$ Institute of Public Health, University of Porto - EPI Unit, Porto, Portugal

\section{Correspondence to} Dr Helena Machado, Centre for Social Studies, University of Coimbra, Colégio de S Jerónimo, Largo D Dinis, Apartado 3087, Coimbra 3000-995, Portugal: helenamachado@ces.uc.pt

Received 20 March 2014 Revised 13 February 2015 Accepted 16 June 2015 Published Online First 2 July 2015

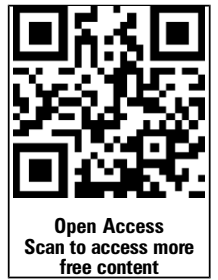

CrossMark

To cite: Machado $\mathrm{H}$ Silva S. J Med Ethics 2015:41:820-824.

\section{ABSTRACT}

The ethical aspects of biobanks and forensic DNA databases are often treated as separate issues. As a reflection of this, public participation, or the involvement of citizens in genetic databases, has been approached differently in the fields of forensics and medicine. This paper aims to cross the boundaries between medicine and forensics by exploring the flows between the ethical issues presented in the two domains and the subsequent conceptualisation of public trust and legitimisation. We propose to introduce the concept of 'solidarity', traditionally applied only to medical and research biobanks, into a consideration of public engagement in medicine and forensics. Inclusion of a solidarity-based framework, in both medical biobanks and forensic DNA databases, raises new questions that should be included in the ethical debate, in relation to both health services/ medical research and activities associated with the criminal justice system.

\section{INTRODUCTION}

Both medical biobanks and forensic DNA databases have the potential to provide great social benefits. Whereas medical biobanks are seen as one of the most promising instruments for fighting disease and improving public health, since they can extend our understanding of illnesses and the development of therapies and treatments for common multifactorial diseases as well as determine why certain groups of people have different reactions to pharmaceutical drugs, ${ }^{1}{ }^{2}$ forensic DNA databases are seen as tools that can improve efforts to detect crime and identify suspects, which is, in turn, expected to reduce crime and increase public safety and security. ${ }^{3-6}$

Medical biobanks involve collection, storage and use of human tissue, genotypes and other biological information derived from this tissue, and a range of data on personal health histories collected from populations of various sizes. Forensic DNA databases involve collection, storage and use of DNA profiles from nominated suspects, convicted offenders, victims, volunteers and other persons of interest to criminal investigation work, so that the profiles can be compared with those obtained from crime scene samples used in crime investigations and law enforcement. In the EU there is considerable variation in the criteria for inclusion of profiles, periods of time, and conditions for their retention and/or deletion among national forensic DNA databases. ${ }^{356}$ Two main groups can be identified: countries with legislation classified as having expansive effects (Austria, Denmark, Estonia, Finland, Latvia, Lithuania, Scotland, Slovakia, and England and Wales); countries with legislation classified as having restrictive effects (Belgium, France, Germany, Hungary, Ireland, Italy, Luxemburg, The Netherlands, Poland, Portugal, Romania, Spain and Sweden). In the group of countries in which legislation is considered to have restrictive effects, the condition generally imposed for inclusion of profiles in databases is that an individual is suspected or convicted of a crime that involves a potential or effective prison sentence, or the fact that the individual subjected to collection of a biological sample has committed crimes that are considered serious. In the expansive group, the inclusion criteria in most countries allow that individuals suspected of any crime can be submitted to sample collection and, consequently, to the inclusion of their respective DNA profiles in the forensic database. ${ }^{6}$

In forensic DNA databases, the type of genetic data stored is potentially only identifying information. However, in some EU jurisdictions, biological samples, together with personal information, are retained for the same period of time as the DNA profiles, which means that, in this situation, the forensic DNA databases are equivalent to biobanks. ${ }^{3-6}$ For the sake of clarification, the concept of biobanks will be used in this paper to refer to the medical field only, and forensic DNA databases to refer to genetic databases used in the criminal justice system.

Although both biobanks and forensic DNA databases have been the subject of considerable economic, political and scientific investment and potentially offer great benefits to society, an intense ethical debate has emerged concerning the risks and harm that may be associated with their use. The complex ethical issues regarding the creation and governance of forensic DNA databases and biobanks have generally been addressed by experts, policy makers, regulators and academic commentators as separate fields of debate and analysis. The separate discussion of ethical problems is usually justified on the basis that forensic DNA databases are used in a completely different context from other biomedical tools and serve other purposes. ${ }^{3}$ In many ways, the idea of maintaining this separation is based on the argument that the ethical aspects of medical biobanks should be framed around individual rights and choices, whereas the debate on forensic DNA databases should be contextualised in terms of the underlying political and social choices. ${ }^{4} 7$ 
This paper critically questions the separation between the ethics of biobanks and forensic DNA databases. Positioning the analysis within the current ethical debate in the medical and forensic arenas, it aims to cross the boundaries between them by exploring the flows between the ethical issues presented in the two domains in the field of public participation, public trust and legitimisation and the subsequent application of the principle of 'solidarity' to medical biobanks and forensic DNA databases.

\section{ETHICS, MEDICAL BIOBANKS AND FORENSIC DNA DATABASES}

In the ethical debate, discussion of medical genetic databases has been framed largely in terms of the autonomy of research participants (principally informed consent and confidentiality) and issues such as commercialisation, ownership and public confidence in the governance of research. ${ }^{8} 9$ The ethical challenges of forensic DNA databases have usually been approached as potential threats to a range of civil rights, such as the right to privacy, liberty and moral and physical integrity, the dignity of persons, and the presumption of innocence. At the heart of the debate related to ethics in the forensic field lies a discussion of the principle of proportionality (ie, the fundamental importance to human beings of respect for their individual rights and the need, in appropriate circumstances, to restrict these rights, either in the general interest or to protect the rights of others). ${ }^{1011}$

A growing number of commentators argue that there is a need to explore in greater depth the continuities and discontinuities between parallel developments and ethical issues in forensic databases and medical biobanks. ${ }^{4}{ }^{7}{ }^{12-14}$ This paper offers a contribution to this perspective by extending the traditional ethical debate on public participation in genetic databases. Various examples of the ethical issues raised by 'trading' between forensic and medical databases can be cited, in particular the fact that genetic information might be used for wider purposes than those for which the databases were originally created, and that privacy and informed consent may be appropriately questioned in both forensic and medical fields. These aspects of the possible flows between medical biobanks and forensic DNA databases and their respective ethical dilemmas will now be discussed, by focusing on two main aspects: the use of genetic data for purposes beyond those that originated the collection of samples; issues of privacy and informed consent.

Biological samples contained in criminal DNA databases can also be used for various forms of scientific and medical research (eg, research into genetic predisposition to violent behaviour), however unclear the ethics might be. Moreover, inclusion of participants' data in genetic databases in which the collection and processing of data may be associated with individual or group characteristics, criminal behaviour or medical conditions may be seen as a situation that restricts individual privacy and leads to discrimination and stigmatisation. ${ }^{4}{ }^{13-16}$ Although speculative automated searches between forensic and medical contexts are banned in all Western jurisdictions, some countries (Denmark and Sweden) have used blood samples collected from newborn babies, which are held in screening biobanks to test for phenylketonuria and other diseases, for DNA tests to identify suspected criminals. These practices raise important challenges in relation to technical and ethical interoperability of medical and forensic biobanks. In addition, commercial players, such as biotech companies, have expressed support and enthusiasm for the expansion of forensic DNA databases, which could potentially create opportunities for the future misuse of samples held in state and privately owned laboratories. ${ }^{17} 18$
Concerns relating to informed consent and privacy are more often emphasised by those writing about medical databases. However, privacy is also the focus of the ethical debate on forensic DNA databases, especially with regard to the retention of samples and profiles of individuals who are not subsequently brought before the courts or in cases when the prosecution fails to establish their guilt. ${ }^{45}$

Informed consent is not typically considered an issue in the context of forensic processing. However, although many jurisdictions in Europe have stipulated that consent is not required when taking a sample from individuals who have committed a crime or who are criminal suspects (eg, Austria, Denmark, Estonia, Finland, Latvia, Lithuania, Scotland, Slovakia, The Netherlands, England and Wales) since they are considered to hold fewer rights given the broader rights of society, other countries (such as Cyprus, France, Germany, Luxembourg, Portugal, the Republic of Ireland and Spain) have decided that informed consent is needed for samples collected during criminal proceedings, even if coercive sampling is allowed. Although collecting samples from convicted offenders tends to be consensual, the same cannot be said of collection of biological material from criminal suspects, as suspects are supposed to be treated as innocent until proven guilty. The storing of samples from nonconvicted suspects is even more problematic, as clearly highlighted by the decision of the European Court of Human Rights, which held, within the $S$ and Marper $v$ United Kingdom [2008] ECHR 1581, that holding DNA samples of individuals who have been arrested but are later acquitted or have the charges against them dropped is a violation of the right to privacy under the European Convention on Human Rights.

It is our view that practices related to informed consent in forensic contexts should be an important area of inquiry, which is still clearly under-addressed and requires further investigation. ${ }^{4} 12$ The following practices support the idea that the ethical debate on the implications of obtaining informed consent would benefit from being examined across the medical and forensic fields: the act of taking a DNA sample is always expected to be performed in accordance with standard medical guidelines; the right to information of data subjects on the foreseeable risks and uncertainties posed by DNA sample collection and DNA profiling, specifying the content and possible and inadmissible uses of the samples, as well as their storage time and availability; and the protection of individuals with regard to processing of personal data and free movement of such data, indicating the procedures associated with the recovery of samples and data, and the terms under which samples and data can be accessed.

\section{PUBLIC PARTICIPATION}

Reflecting the separate discussion on the ethics of forensic DNA databases and medical biobanks, public participation or the involvement of citizens in genetic databases has been approached differently in the two fields of forensics and medicine. The question of public participation is a key issue in the governance of genetic databases and has been framed in two different ways: as people providing research material for genetic databases, and as people becoming co-decision-makers in these projects. ${ }^{13}$ These two aspects of public participation are generally considered important to the involvement of citizens in medical research projects. In the case of forensic genetic databases, the debate on public participation has been restricted to public involvement in governance and policy decisions- that is, the perception of citizens as co-decision makers-and therefore the assumption that public concerns about human rights and 
civil liberties should be identified and, in the light of this, the acceptable conditions for establishing and governing a forensic DNA database should be amended. ${ }^{6}$ 14-17 1920 This differentiation between the concept of public participation in biobanks and forensic DNA databases can essentially be explained by the fact that the latter is associated with the compulsory collection of profiles and samples from individuals who have been arrested, accused and convicted of crimes, for policing purposes, whereas biobank records are assumed to rely on voluntary participation. ${ }^{4} 712$

In our view, completely separating the ethical issues regarding the governance of genetic databases in medicine from the DNA databases used in criminal investigation restricts the ways in which public participation is designed and conceived, for three main reasons. First, the dichotomy of voluntary and compulsory participation fails to consider certain concrete situations which do not fall clearly into one category or the other (eg, volunteers or victims of crime who provide DNA samples for criminal genetic databases, as well as disease registries and investigations into public health emergencies when data have been collected without the need for individual informed consent). ${ }^{7} \quad 13 \quad 15$ Second, this contraposition between DNA samples collected by compulsion (associated with criminal genetic databases) and the voluntary provision of human biological material (linked to medical databases) is based on an individualistic approach to ethics which focuses mainly on the potential restriction of individual civil rights, while failing to consider collective and political concerns, such as institutional oversight, public trust, and transparency in the governance of genetic databases. Third, the emphasis on 'free choice' on the part of those contributing to biobanks has been extensively criticised, and several commentators have shown that the concept of 'voluntary participation' is ambiguous and unclear. ${ }^{1} 4{ }^{4} 171820$ In the forensic criminal field, refusal to be a volunteer might be the basis for being added to the list of 'suspects'. ${ }^{4}$ The so-called practice of 'DNA dragnets' in criminal investigation consists of asking hundreds, even thousands, of people for their blood or saliva, in the hope of finding the one person whose DNA matches DNA left at a crime scene. In addition, recent studies indicate that the automatic association of 'compulsory participation' with criminal genetic databases is also problematic: not only may convicted offenders see the inclusion of their individual genetic profile as a means of protecting their individual rights and increasing their chances of exoneration, but ordinary citizens may also be willing to voluntarily donate a sample for profiling and inclusion in a criminal DNA database because of the perceived benefits of protecting both society and individuals from crime. ${ }^{11} 21$

Thus, the ethical debate about public participation in medical biobanks can be meaningfully applied to public participation in forensic arenas. In the next section we explore how flow between the ethical issues presented in the two domains translates into a renewed conceptualisation of public trust and legitimisation. Our argument is sustained by empirical evidence generated from recent studies on public attitudes to medical biobanks and forensic genetic databases.

\section{PUBLIC TRUST AND LEGITIMISATION}

In the recent political and academic debate, strengthening trust in genetic databasing has been presented as imperative to the legitimacy and maintenance of biobanks and forensic DNA databases. ${ }^{5}{ }^{16}$ Empirical studies on public attitudes to medical biobanks and forensic genetic databases have consistently shown high levels of trust in scientific institutions, a positive vision of genetic databasing and its expected results, strong motivation to donate biological material based on feelings of altruism and wanting to help others, and the public perception that the forensic use of medical biobanks does not affect trust in healthcare services. ${ }^{1420} 22-24$ However, the perception of societal benefits and the confidence placed in genetic databasing, in both forensic and medical fields, is challenged by scarcity of information and concerns about lack of control and insufficient or unclear regulations concerning safeguarding individuals' data and supervising the access and uses of genetic data.

This flow between public attitudes in the field of medicine and forensics translates into a renewed conceptualisation of public trust and legitimisation, in four complementary ways. First, it draws attention to the responsibility of scientific and political institutions. Literature on bioethics has highlighted the importance of incorporating biobanks and forensic databases into creditable institutions that have the capacity to support them, managed by trustworthy researchers, singling out universities and research centres or national forensic medicine institutions. ${ }^{9} 22$ The need to regulate and implement a policy of truth and transparency for the activities of biobanks and forensic DNA databases has also been recognised, which safeguards individual privacy and upholds the trust placed in them. Detailing the interests of the many players involved in the respective governance and clarifying the conditions for using, accessing and disseminating data represent steps forward in this direction. Second, it highlights the importance of providing accurate and timely information to data subjects, in particular about the purpose and objectives of the biobank and its governance structures, possible and inadmissible uses of the samples, variables to be registered in the database, storage time and availability of samples, type of samples stored, procedures associated with the recovery of samples and data, terms under which samples and data can be accessed, rights of individuals, and a list of the foreseeable risks and benefits. Third, it asks for assurance that the public will be involved and protected by consulting their opinions about the functioning of biobanks and forensic DNA databases. Finally, it calls for adjustment between the expectations and responsibilities of all players involved to the reality of medical research and also to the use of genetic databases to support criminal investigation and prosecution activities.

Overall, fostering public trust and legitimisation are a matter of addressing not only individual rights and needs, but also the rights and needs of communities and social groups. We therefore argue that it is necessary to move beyond the individualistic approach to ethics in which the focus has been the debate on the restriction of civil rights, since the aim of genetic databases is to act in the public interest. ${ }^{7} 1517$ In addition, actions directed towards a collective rather than an individual perspective may exist, on the part of both 'non-criminals' whose profiles may be stored in databases and individuals convicted of crimes whose profiles (and, in some jurisdictions, samples as well) are included in forensic DNA databases. ${ }^{11} 1424$ Actions of this nature may also emerge in healthcare, particularly in studies involving disease registries and investigations into public health emergencies in which the collective dimension and public interest overshadow individual responsibilities and protection of the rights of individuals. 24917182025

The perception of genetic databases as civic projects and arenas for negotiation between the interests of public and private institutions and individual and collective rights and duties calls for community ethics, as has been advocated in the context of medical and research biobanks. ${ }^{8} 925$ We propose a renewed ethical debate by arguing that such a solidarity-based approach could be meaningfully extended to public participation in forensic DNA databases, as explored in the next section. 


\section{THE PRINCIPLE OF SOLIDARITY}

Solidarity has been discussed as an emerging concept in bioethics, ${ }^{25} 26$ advocating community ethics associated with practices and commitments that are shared, in financial, social and emotional terms, with common assets, combining individual and collective responsibilities and relying on the contributions of all to ensure that all will benefit. An approach based on solidarity also includes introducing mechanisms for public participation guided by the principles of respect, veracity and transparency, prioritising research that is not designed for financial gain, developing harm mitigation strategies, and ensuring that citizens may exercise their right to information. It involves not only technical and scientific issues but also a discussion of the purposes of dignified and beneficial data processing, guided by the following main principles, which may cross the borders between medical and forensic genetic databases: reinforcement of the subject's right to be informed and to give consent; transparency with regard to the purposes, risks, benefits and actors involved in processing personal data; monitoring, supervision and accountability by independent citizens and institutions; management of conflicts of interest by balancing public and private interests and individual and collective interests; consultation of the public. ${ }^{17}$

Incorporation of the principle of solidarity in relation to forensic DNA databases might be particularly relevant regarding the forensic uses of medical biobanks and in relation to the exchange of DNA data between countries for forensic purposes. Although all Western criminal jurisdictions ban the speculative automated exchange of information between forensic and medical contexts, in exceptional circumstances (for instance, for identification of victims of mass disasters and catastrophes) forensic use of medical biobanks is allowed. ${ }^{4}$ EU Law, through Decisions 2008/615/JHA and 2008/616/JHA (EU Council, 2008), establishes a pan-European system for the transnational exchange of forensic genetic data between EU countries, for the purpose of combating cross-border crime, terrorism and illegal immigration. More than 10 million individuals' DNA profiles will be exchanged between agencies in all EU countries on a routine and automated basis, in a context marked by lack of transparency and accountability. ${ }^{6}$

Inclusion of a solidarity-based framework may reinforce public participation in both medical and forensic genetic databases, and ensure greater transparency in terms of access to, and use of, personal data and the independence of controllers. As suggested by Prainsack and Buyx, ${ }^{25}$ the credibility of biobanks and the trust placed in them are essential to achieving a threetier model of solidarity: on an interpersonal level, it is necessary for people to be often willing to accept the costs (the risk of losses and the inconvenience of participating) in order to help others on the basis of the notion of similarity and the fact that solidarity-based biobanks are not unduly exploited for financial gain; on a group level, the participants and the biobanks become partners in projects that focus on their common interests and negotiate common forms of conduct in order to achieve shared objectives, rather than merely acting as parties to a contract; on a contractual level, the obligations arising out of the regulation and governance of biobanks are respected.

\section{CONCLUSION}

Solidarity raises new questions that should be included in the ethical debate, with regard to crime prevention, investigation and prosecution as well as healthcare services and research. They include the balance between individual and collective benefits and responsibilities, and reflections on the fair, efficient and effective allocation and use of existing genetic databases in different national contexts in order to offset inequalities between social groups and Member States. It is a matter of proactively assessing the current and future benefits and risks for the public in a context in which biobanks and forensic DNA databases are seen as social entities or assets that must make their conduct explicit to the participants on the basis of community values and the social, political and ethical consequences of medical research or criminal investigation. Certain questions need to be clarified and analysed in greater detail: rights of ownership with regard to personal data and biobanks; the unequal distribution of risks and benefits among populations; conflicts of interests involving the protection of individual rights; the relationship between public and private biobanks and between research, industrial and/or business interests and criminal investigation work; and the ways in which the public is represented before independent controllers.

This discussion might be also framed to serve present or future public assets indispensible to other community and public benefits, such as the fight against crime or the promotion of healthcare. The balance between individual and collective rights, the state-citizen relationship, and notions of human nature and social commitments to what is worth protecting, and the reasons for this, involves complex values and normativities that are culturally and historically bounded and need to be empirically explored. This will allow public scrutiny of the work of biobanks and forensic DNA databases and the responsible dissemination of results to individuals, the scientific community, and the justice and healthcare systems.

\section{Acknowledgements The authors would like to thank Barbara Prainsack for} valuable comments on a draft of this paper.

Contributors HM and SS designed the outline of the argument and researched the bibliography. HM structured the global argument and developed the topics related to forensic DNA databases. SS developed the topics related to medical biobanks. Both authors developed the analysis of flows between biobanks and forensic DNA databases and contributed to the discussion of 'public participation', 'public trust and legitimisation' and 'solidarity'.

Funding This study was supported through FEDER from the Operational Programme Factors of Competitiveness - COMPETE and through national funding from the Foundation for Science and Technology - FCT (Portuguese Ministry of Education and Science) within the grants IF/00829/2013 (to HM) and IF/00956/ 2013 (to SS).

\section{Competing interests None declared.}

Provenance and peer review Not commissioned; externally peer reviewed.

Open Access This is an Open Access article distributed in accordance with the Creative Commons Attribution Non Commercial (CC BY-NC 4.0) license, which permits others to distribute, remix, adapt, build upon this work non-commercially, and license their derivative works on different terms, provided the original work is properly cited and the use is non-commercial. See: http://creativecommons.org/ licenses/by-nc/4.0/

\section{REFERENCES}

1 Pang T. Genomics for public health improvement: relevant international ethical and policy issues around genome-wide association studies and biobanks. Public Health Genomics 2013;16:69-72.

2 Gaskell G, Gottweis H, Starbaum J, et al. Publics and biobanks: pan-European diversity and the challenge of responsible innovation. Eur J Hum Genet 2013;21:14-20.

3 Patyn A, Dierickx K. Forensic DNA databases: genetic testing as a societal choice. J Med Ethics 2010;36:319-20.

4 Cho MK, Sankar P. Forensic genetics and ethical, legal and social implications beyond the clinic. Nat Genet 2004;36(Suppl):S8-12.

5 Van Camp N, Dierickx K. The retention of forensic samples: a socio-ethical evaluation of current practices in the EU. J Med Ethics 2008;34:606-10.

6 Santos F, Machado H, Silva S. Forensic DNA databases in Europe: is size linked to performance? Life Sci Soc Policy 2013;9(12):1-13. 
7 Williams G. Bioethics and large-scale biobanking: individualistic ethics and collective projects. Genomics Soc Policy 2005;1:50-66.

8 Meslin EM, Garba I. Biobanking and public health: is a human rights approach the tie that binds? Hum Genet 2011;130:451-63.

9 Cordell S. The biobank as an ethical subject. Health Care Anal 2011;19:282-94.

10 Guillén M, Lareu MV, Pestoni C, et al. Ethical-legal problems of DNA databases in criminal investigation. J Med Ethics 2000;26:266-71.

11 Machado H, Silva S. Would you accept having your DNA profile in the National Forensic Database? Why? Forensic Sci Int Genet 2014;8:132-6.

12 Machado H, Silva S. Informed consent in forensic DNA databases: volunteering, constructions of risk and identity categorization. Biosocieties 2009;4:335-48.

13 Tutton R. Constructing participation in genetic databases. Citizenship, governance, and ambivalence. Sci Technol Human Values 2007;32:172-95.

14 Bexellius C, Hoyer K, Lynoe N. Will forensic use of medical biobanks decrease public trust in healthcare services? Some empirical observations. Scand I Public Health 2007;35:442-4.

15 Simon CM, L'Heureux J, Murray JC, et al. Active choice but not too active: public perspectives on biobank consent models. Genet Med 2011;13:821-31.

16 Salter B, Jones M. Biobanks and bioethics: the politics of legitimation. J Eur Public Policy 2005;12:710-32.

17 Widdows $\mathrm{H}$, Cordell S. Why communities and their goods matter: illustrated with the example of biobanks. Public Health Ethics 2011;4:14-25.
18 Lunshof JE, Chadwick R, Vorhaus DB, et al. From genetic privacy to open consent. Nat Rev Genet 2008;9:406-11.

19 Silva S, Machado H. Trust, morality and altruism in the donation of biological material: the case of Portugal. New Genet Soc 2009;28:103-18.

20 Forsberg JS, Hansson MG, Eriksson S. Changing perspectives in biobank research: from individual rights to concerns about public health regarding the return of results. Eur J Hum Genet 2009;17:1544-9.

21 Machado H, Santos F, Silva S. Prisoners' expectations of the national forensic DNA database: surveillance and reconfiguration of individual rights. Forensic Sci Int 2011;210:139-43.

22 Gamero JJ, Romero JL, Peralta JL, et al. A study of Spanish attitudes regarding the custody and use of forensic DNA databases. Forensic Sci Int Genet 2008;2:138-49.

23 Haddow G, Cunningham-Burley S, Bruce A, et al. Generation Scotland: consulting publics and specialists at an early stage in a genetic database's development. Crit Public Health 2008;18:139-49.

24 Wilson-Kovacs D, Wyatt D, Hauskeller C. 'A Faustian bargain?' Public voices on forensic DNA technologies and the National DNA Database. New Genet Soc 2012;31:285-98.

25 Prainsack B, Buyx A. A solidarity-based approach to the governance of research biobanks. Med Law Rev 2013;21:71-91.

26 Chadwick R, Berg K. Solidarity and equity: new ethical frameworks for genetic databases. Nat Rev Genet 2001;2:318-21. 